\title{
In vitro validation of the luminal measurement of a novel catheter based moulding technique
}

\author{
S C Eccleshall, P J Jordan, N P Buller, J N Townend
}

\begin{abstract}
Objective-To investigate a modified angioplasty balloon catheter, which uses a novel balloon polymer to produce luminal moulds.

Design-The catheter was tested in polyurethane phantoms of diameter 1.5 to 4.0 $\mathrm{mm}$. Inflations were to 1.4 atmospheres for 20 seconds at $37^{\circ} \mathrm{C}$. The moulds were viewed by reinflating the balloon to 0.34 atmospheres and quantified using macrophotography and caliper measurement.

Results-Evidence of systematic error was found with lumen diameters $\leqslant 2.0$ $\mathrm{mm}$, accuracy being 0.32 to $0.80 \mathrm{~mm}$ and precision 0.23 to $0.24 \mathrm{~mm}$. However, between 2.5 and $4.0 \mathrm{~mm}$ the accuracy of measuring luminal diameters was 0.01 $\mathrm{mm}$, the precision $0.06 \mathrm{~mm}$, and the absolute mean error $0.05 \mathrm{~mm}$. The results for percentage diameter stenosis were $-1.15 \%, 0.86 \%$, and $1.21 \%$, and for lesion length they were $0.20,0.60$, and $0.41 \mathrm{~mm}$, respectively.

Conclusions-The prototype catheter shows a high degree of accuracy and precision in phantoms of diameter 2.5 to 4.0 $\mathrm{mm}$ - the range within which most interventional work is performed. Further work on this technique as a method of direct three dimensional moulding of the coronary artery lumen is warranted. (Heart 1999;81:206-211)
\end{abstract}

Keywords: moulds; luminal moulding; balloon catheter; coronary artery

Atheromatous plaque within a coronary artery produces complex deformation of the vessel which can be difficult to appreciate using current imaging techniques. However, accurate luminal measurement is necessary when planning treatment and is essential for the practice of angioplasty and stenting. The most widely used imaging method is coronary angiography, which requires multiple orthogonal views, is significantly limited by technical and anatomical difficulties and errors of interpretation, and provides a two dimensional "lumenogram". Intravascular ultrasound produces a two dimensional cross sectional view of the lumen with additional information on the arterial wall but has technical limitations such as the trade off between resolution and penetration, as well as difficulties related to catheter movement and positioning and image interpretation. ${ }^{1}$

We have investigated a prototype catheter (Boston Scientific Corporation, Boston, Massachusetts, USA) which offers the possibility of rapid acquisition of a luminal mould. The balloon is constructed of a novel polymer (a blend of polybutylene terephthalate (PBT) and polyethylene terephthalate glycol (PETG)) which moulds to the internal surface of a hollow structure when subjected to a low pressure inflation at $37^{\circ} \mathrm{C}$. The polymer has the property of "deformation memory" such that deflation, removal, and subsequent reinflation at a lower pressure will reproduce the mould. This stored mould may be removed using a gentle longitudinal stretch and the balloon reused.

We have examined the accuracy, precision, and long term memory of this novel luminal moulding technique in simple tube and concentric stenotic phantoms.

\section{Methods}

\section{MATERIALS}

The catheter

The current prototype catheter (fig 1) uses the new polymer in a modification of the "over the wire" design of angioplasty balloon for standard coronary use. The balloon is bonded proximally to an outer tube in continuity with the inflation port of the manifold and distally to an inner tube, which passes through an O-ring in the manifold. This allows the inner tube to move relative to the outer tube as the balloon shortens during moulding. The prototype balloon has a profile of $1.4 \mathrm{~mm}$, a length of 80 $\mathrm{mm}$, and in its current version is designed to

Birmingham B15, UK

S C Eccleshall

N P Buller

University

Department of

Cardiovascular

Medicine, University

of Birmingham,

Birmingham, UK

P J Jordan

J N Townend

Correspondence to:

Dr Eccleshall.

Accepted for publication 5 October 1998

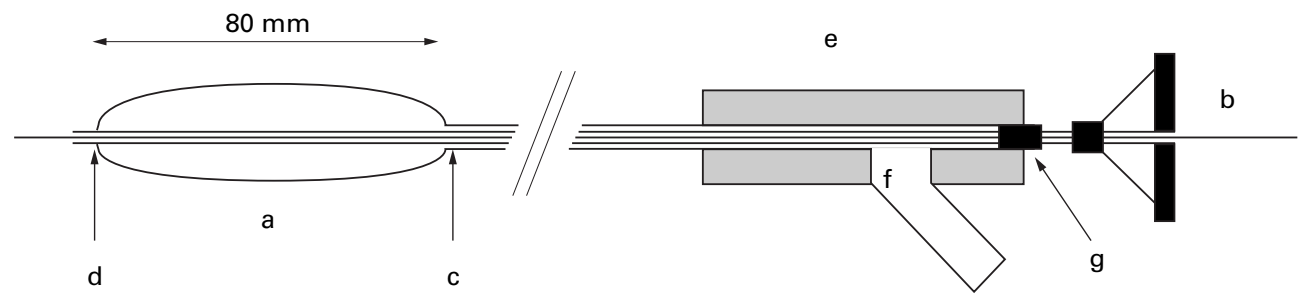

Figure 1 The catheter: the balloon (a) with central guidewire (b) attaches proximally to the outer tube (c) and distally to the inner tube (d). The outer tube is in continuity with the manifold (e) producing a lumen between the balloon and inflation port $(f)$. The inner tube passes through the manifold proximally at an $O$-ring $(g)$, which allows it to move freely during inflation and balloon shortening. 
A

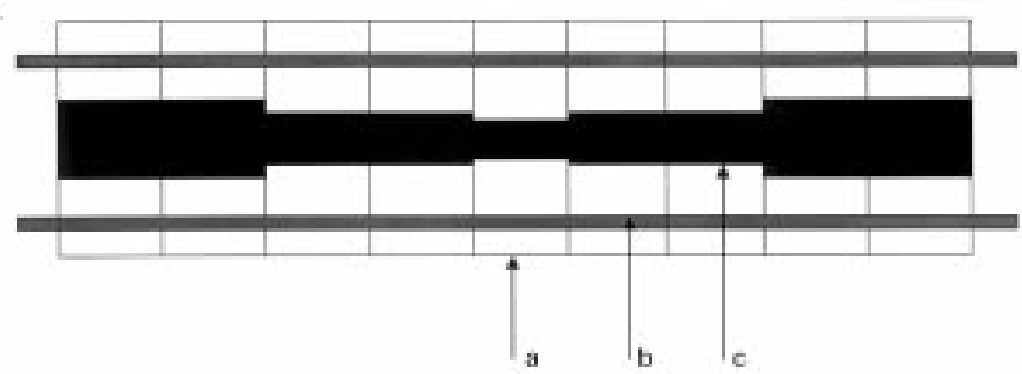

B

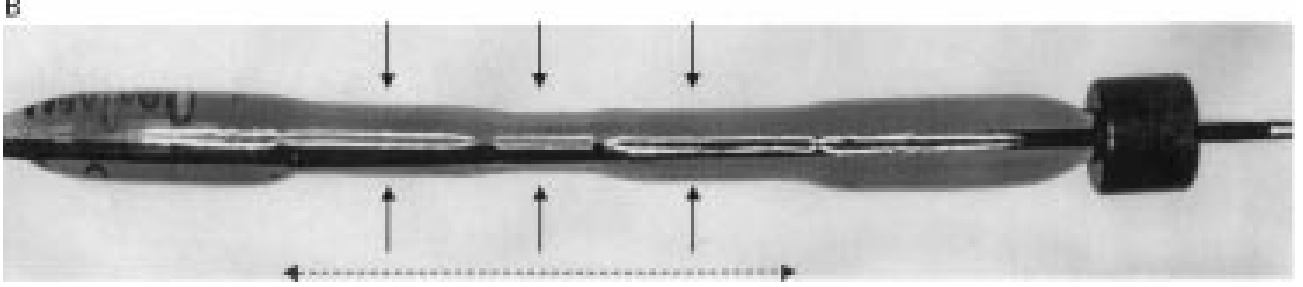

Figure 2 (A) Diagram illustrating an assembled complex phantom. The discs of Tufset (a) are mounted on metal rods (b) to produce a stenotic lumen (c). (B) Photograph of a mould of a complex phantom. The balloon is mounted on a mandrel adjacent to the calibration cylinder. Diameters are measured as shown (solid arrows). Lesion length is measured between the indentations (dotted arrow).

mould to luminal contours in the range 1.5 to $4.0 \mathrm{~mm}$.

\section{Phantoms}

To examine luminal diameter measurement by the catheter, six simple tubular phantoms were constructed from $60 \mathrm{~mm}$ lengths of a $20 \mathrm{~mm}$ diameter cylinder of "Tufset" (RS Electronics, Birmingham, UK) - a rigid polyurethane with good dimensional stability which may be machined to close tolerances. Each length was precision drilled centrally through the long axis, producing phantoms with internal diameters in the range 1.5 to $4.0 \mathrm{~mm}$ (in $0.5 \mathrm{~mm}$ increments). Heat distortion was minimised by using a slow drill speed (140 rpm) and lubrication. Radial vents of $1.0 \mathrm{~mm}$ diameter were drilled through the phantom into the central lumen at $10 \mathrm{~mm}$ intervals to allow water or air trapped during inflation to escape. To study the measurement of luminal stenosis, 5 to $10 \mathrm{~mm}$ thick discs of Tufset with diameters in the working range identified above were assembled to produce more complex phantoms (fig $2 \mathrm{~A}$ ).

To assess thermal stability, the simple tubular phantoms were photographed in cross section four times at $20^{\circ} \mathrm{C}$ (the temperature of manufacture) and then at $37^{\circ} \mathrm{C}$ (the working temperature), and the luminal diameter measured in four planes in each image, using the photographic procedure described below. The results gave mean signed differences of -0.032 to $+0.013 \mathrm{~mm}$, with an overall absolute mean error (unsigned mean difference) of $0.012 \mathrm{~mm}$.

\section{EXPERIMENTAL PROCEDURE}

\section{Moulding technique}

The catheter was primed with dye coloured sterile water and connected by the inflation port to a low reading pressure gauge ( 0 to 2 atm, 0 to $35 \mathrm{psi}$ ), a three way tap, and a $10 \mathrm{ml}$ Luer lock syringe. The phantoms were immersed in a water bath at $37^{\circ} \mathrm{C}$ and the catheter placed within them, using a guidewire when necessary to facilitate passage through stenotic sections. An inflation to 1.4 atm (20 psi, the moulding pressure recommended by the manufacturer) for 20 seconds was performed, with the O-ring open to allow movement of the inner tube as the balloon shortened. The catheter was then deflated, removed, and reinflated at $0.34 \mathrm{~atm}$ ( $5 \mathrm{psi}$, the minimum pressure required to fully expand the mould) in order to photograph the balloon. After photography the balloon was restretched by firmly holding the proximal and distal bond sites and applying a gentle longitudinal force until resistance was met. Reinflation to 0.34 atm confirmed the balloon had returned to an unmoulded state. Ten catheters were used to examine the six simple tubular phantoms (a total of 36 inflations) and the five complex phantoms (30 inflations).

\section{Photographic assessment}

The balloon was clamped in a mounting block designed to revolve by $22.5^{\circ}$ per turn. A mandrel was introduced through the distal central guidewire port to minimise error introduced by deviation of the balloon out of the axis of rotation. A steel cylinder ( $4.8 \mathrm{~mm}$ diameter) was positioned on the mandrel adjacent to the balloon for calibration purposes. A Canon EOS 100 camera body was mounted directly above the balloon at a fixed distance using a copy stand, and high definition photography performed with a converter (Canon Life Size Converter EF), a compact macro lens (Canon

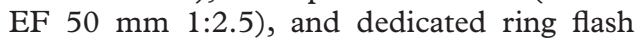
(Canon Macro Ring Lite ML-3). The edge of the balloon was used as the focal point and photographs taken after each rotation for a total of eight images per mould. High resolution film was used (Kodak Ektar 100) and all processing was carried out at the same photographic laboratory. The final image had a magnification of approximately 3.3. 
Measurements

The photographs of the simple tube moulds were measured at $10 \mathrm{~mm}$ intervals along the balloon's length using calipers accurate to 0.01 $\mathrm{mm}$. Measurements were made at the midpoint of each segment in the complex phantom moulds (fig 2B). The central balloon marker was used as a reference point to ensure the same positions were measured in every photograph of a given mould. The length of the segment of minimum luminal diameter and the total lesion length were measured using the indentations of the balloon profile at the transition points. The calibration cylinder was also measured in each photograph to provide a scaling factor.

\section{Mould storage}

To examine the long term memory of the polymer, eight balloons selected at random were restudied seven or more days after the initial moulding and the two sets of moulds compared.

\section{STATISTICAL ANALYSIS}

Data analysis

Measurements were entered onto a personal computer. To allow direct comparison with the phantoms the photographic measurements were multiplied by a scaling factor calculated from the geometric mean of all the measurements of the calibration steel cylinder. The eight values for a given point on the balloon were then used to calculate a mean representing one balloon measurement of luminal diameter or length. For complex phantoms the change in luminal diameter was taken as the difference between the diameters measured in the neighbouring sections.

\section{Random error}

The error inherent in the photographic imaging and quantification methods was determined by calculating 2 SDs of all measurements of the calibration cylinder for that stage and multiplying by the scaling factor.

\section{Systematic error}

The level of agreement for the simple tubular phantoms was examined using a modification of the Bland and Altman technique plotting the signed differences against the known phantom values. $^{2}$

\section{Accuracy and precision}

The mean signed difference between the balloon and phantom for a given dimension is taken to represent the accuracy, 1 SD the precision, and the unsigned mean difference the absolute mean error. Radial reproducibility of the catheter in concentric phantoms (the variation between values after rotation for each point in a single inflation) is defined as twice the largest SD of a single mean for that diameter. Longitudinal reproducibility is the variation in measurement of a length after rotation, calculated as twice the largest SD for that length.
Mould storage

The stored moulds were compared with the original using a paired $t$ test (with a significance level of $5 \%$ ). The mean (SD) signed and unsigned differences between the original and stored moulds were also calculated.

\section{Results}

BALLOON CHARACTERISTICS

Of the 10 balloons used, three developed leaks related to mechanical trauma from the rigid phantoms, having been used successfully six to nine times. Another balloon was found to have a permanently underexpanded central portion which persisted after repeated inflations at $37^{\circ} \mathrm{C}$ outside the phantoms with the O-ring open, suggesting a problem with the moulding capability of the balloon. This catheter was therefore not used in the study.

RANDOM ERROR

The error inherent in the quantification method (2 SD of all measurements of the calibration cylinder multiplied by the scaling factor) was 0.08 and $0.07 \mathrm{~mm}$ for the two experimental stages. The scaling factor was 0.303 for tube phantoms and 0.301 for complex phantoms (giving magnification values of 3.30 and 3.32 respectively).

\section{SYSTEMATIC ERROR}

Figure 3A shows the relation between the balloon and phantom diameters in the range 1.5 to $4.0 \mathrm{~mm}$. The balloon-phantom mean (SD) signed difference for the whole range was an overestimate of $0.19(0.34) \mathrm{mm}$ (representing the accuracy and precision respectively) and highlights systematic error at phantom diameters of $<2.5 \mathrm{~mm}$. At a phantom diameter of $2.0 \mathrm{~mm}$ the overestimation was $0.32(0.23)$ $\mathrm{mm}$, and at $1.5 \mathrm{~mm}$ it was $0.80(0.24) \mathrm{mm}$.

\section{ACCURACY AND PRECISION}

Simple tubular phantoms

In the range 2.5 to $4.0 \mathrm{~mm}$ the balloonphantom mean (SD) difference was 0.01 (0.06) $\mathrm{mm}$. The absolute mean error for this range was $0.05 \mathrm{~mm}$ and the radial reproducibility $(2 \times$ the maximum $\mathrm{SD}$ of all the inflations for each phantom diameter) was 0.08 to $0.11 \mathrm{~mm}$.

\section{Complex phantoms}

The mean difference and standard deviation (accuracy and precision) of measuring the luminal diameters in complex phantoms in the working range identified above was -0.02 and $0.07 \mathrm{~mm}$ and the absolute mean error was 0.05 $\mathrm{mm}$ (fig 3B). The assessment of change in luminal diameter $\leqslant 1.0 \mathrm{~mm}$ is shown in fig $3 \mathrm{C}$ - the mean signed difference (SD) between phantom luminal change and balloon measurements was $-0.02(0.06) \mathrm{mm}$ and the unsigned mean difference was $0.05 \mathrm{~mm}$. Percentage diameter stenosis calculated from the maximum and minimum lumen diameters for each phantom was measured to an accuracy of $-1.15 \%$, with a precision of $0.86 \%$ and an absolute mean error of $1.21 \%$. 
A

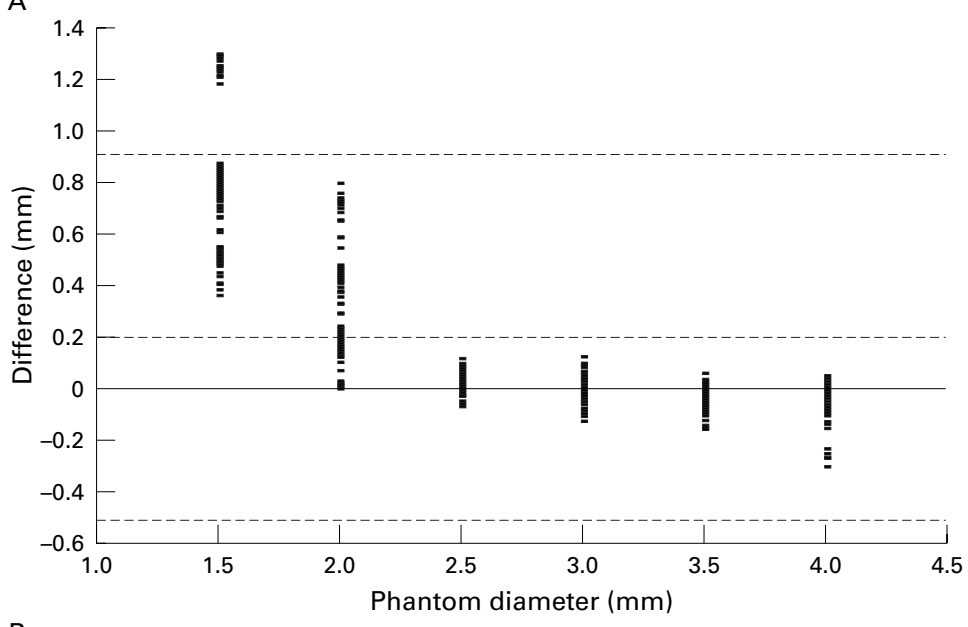

B

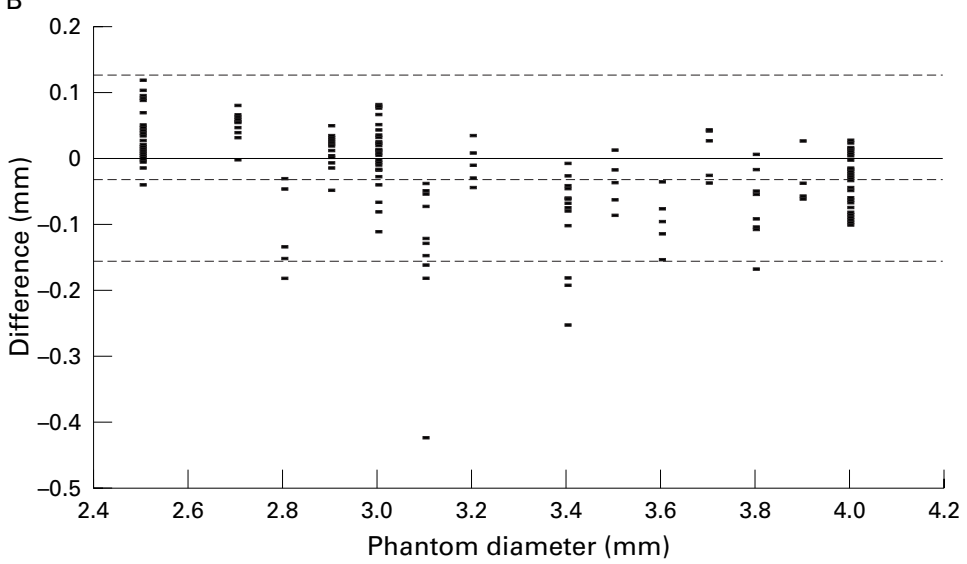

C

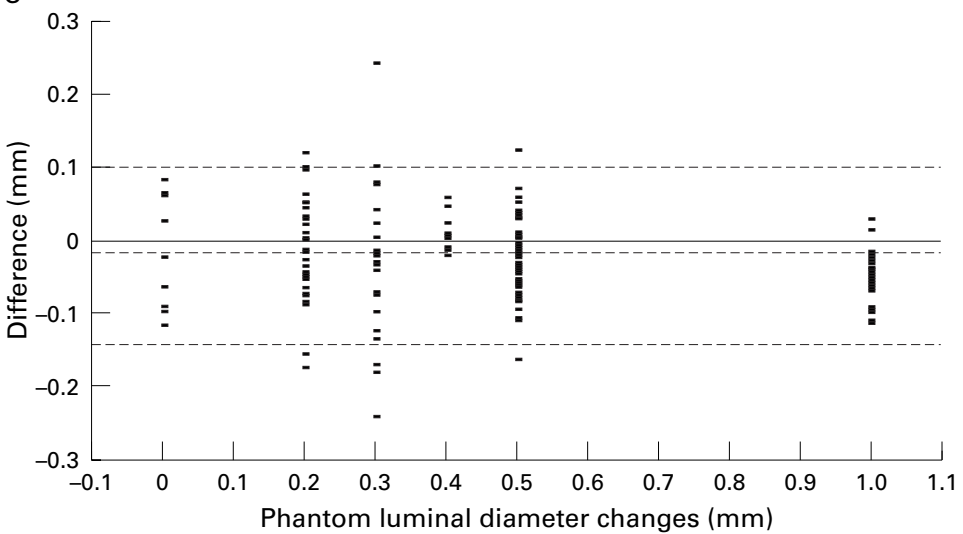

Figure 3 Modified Bland-Altman plots. (A) The difference between the balloon and phantom for simple lumen diameters in the range 1.5 to $4.0 \mathrm{~mm}$. (B) The difference between the balloon and phantom diameters for complex models in the range 2.5 to $4.0 \mathrm{~mm}$. (C) The difference between the balloon and phantom for changes in luminal diameter $\leqslant 1.0 \mathrm{~mm}$. The dotted lines represent the mean signed difference $\pm 2 S D$.

Lesion lengths

Lengths measured by the catheter had a mean difference (SD) of $0.20(0.60) \mathrm{mm}$ and an unsigned mean difference of $0.41 \mathrm{~mm}$. Longitudinal reproducibility was 0.19 to $1.10 \mathrm{~mm}$.

\section{Mould storage}

Remeasuring the stored mould seven or more days later (mean 24.75 days, range 7 to 54 ) resulted in a mean (SD) difference of -0.04 (0.09) $\mathrm{mm}$ and an absolute mean error of 0.06 $\mathrm{mm}$. No mould was significantly different by $t$ testing (all $\mathrm{p}$ values $>0.5$ ).

\section{Discussion}

THE CATHETER

We have shown that the prototype catheter incorporating the novel PBT/PETG polymer balloon has a high degree of accuracy and precision in the measurement of phantom luminal diameter and stenoses over the range 2.5 to 4.0 $\mathrm{mm}$. The catheter can detect changes in luminal diameter of $0.2 \mathrm{~mm}$, suggesting it may be capable of accurately moulding the complex eccentric three dimensional lumens found in vivo. Lesion length is measured accurately by virtue of the indentations made in the balloon mould.

The immediate luminal mould offered by the catheter might be an advantage in the assessment of coronary artery lesions and in the appreciation of the complex encroachment of the vessel lumen. Stenoses of an intermediate or uncertain severity or length may be inspected in more detail to guide therapeutic decision making. Visualisation of the postintervention minimum luminal diameter could allow optimisation of stent deployment. The balloon may be reused a number of times in the same patient and the final mould stored.

Some of the disadvantages of the catheter, similar to those of intravascular ultrasound, relate to the need to instrument the vessel for merely diagnostic reasons, with a resultant "Dotter" effect, ${ }^{3}$ plus the additional potential for vessel trauma from "low pressure angioplasty." The mould produced by the catheter, while being an accurate measure of luminal dimensions, still has the limitation of being a "lumenogram," and, like angiography, will therefore underestimate the extent of atherosclerosis. Similarly, the moulding technique employed by the catheter would not be expected to identify mobile or easily compressible intraluminal projections such as dissection flaps or thrombus. Measurement of true vessel dimensions - the media-media distance as measured by intravascular ultrasound-would not be available for the guidance of atheroablative techniques, while the lumen outside an underexpanded stent would not be identified. In its present design, the balloon will have problems moulding lumens with diameters less than $2.5 \mathrm{~mm}$ owing to the systematic error shown. As the catheter design improves, a reduction in size may be expected, to allow the accurate moulding of smaller luminal diameters, but access will always be limited by the balloon profile. There will be a delay to direct visualisation of the mould (the time required to remove and reinflate the balloon), but this is comparable to the time necessary to acquire online three dimensional intravascular ultrasonic images.

The problem of quantification of a three dimensional structure is a challenge-the system of photography described here, reducing the mould to a two dimensional image to measure diameter and length, is appropriate for in vitro validation purposes only. True three dimensional analysis would require knowledge 
of the vessel's centreline coordinates in three planes, as well as accurate measurement of lumen cross sectional area and vessel length. At present there is no true three dimensional imaging technique available for assessment of coronary arteries, and the question of the value of such a method as an aid to cardiologists in diagnosis and intervention has not been addressed. Three dimensional intravascular ultrasound reconstruction in effect represents two dimensional cross sectional information in a longitudinal format, allowing more rapid identification of the region of interest and volumetric analysis of the plaque and lumen, but is still presented as a two dimensional image. Should a three dimensional imaging technique be shown to be robust in a clinical setting, cardiologists would, for the first time, need to assess whether such a three dimensional representation of the coronary artery lumen provides more useful information than that gained using multiple two dimensional images.

Further development could produce balloons able to mould smaller lumens, thereby increasing the range over which the catheter could be used as an accurate method of luminal measurement. The current design employing coaxial tubes and an O-ring is rather bulky and is to be replaced in the next generation of prototype catheter. The manufacturing process used determines the upper limit of the range in the prototype catheters. Visualisation and accurate measurement of larger vessels (for example, saphenous vein grafts) could be performed using larger balloon sizes.

\section{COMPARISON WITH CURRENT IMAGING}

TECHNIQUES

The introduction of computer based quantitative coronary angiography systems has greatly reduced the error due to observer bias in the angiographic assessment of coronary artery disease. ${ }^{4}$ However, there remain many limitations ranging from anatomical constraints to image acquisition and processing. Motion artefact, vessel foreshortening, overlapping branches, and bifurcation points can hamper both visualisation and analysis of lesions, limiting segments suitable for automated arterial border detection to only $52.5 \% .{ }^{5}$ Image distortion and the choice of calibration method can also affect the results of luminal measurement using quantitative coronary angiography. In vitro validation studies of quantitative coronary angiography have quoted marked variations in accuracy and precision (table 1), showing our results in a favourable light.

Intravascular ultrasound, which has been shown to be an accurate method of identifying the extent and degree of atherosclerosis, suggests that there is angiographic underestimation of disease. ${ }^{13-15}$ However, ultrasound imaging suffers from technical problems (such as the trade off between resolution and penetration) and image interpretation. ${ }^{1}$ Catheter position is important, as angulation or lateral displacement of the transducer can affect area measurements by $20-30 \%,{ }^{16-18}$ as can non-uniform rotational distortion. ${ }^{19}$ Initial
Table 1 Comparison of the results using the catheter with published results for quantitative coronary angiography (QCA) systems

\begin{tabular}{|c|c|c|}
\hline System & Accuracy (mm) & Precision $(\mathrm{mm})$ \\
\hline \multicolumn{3}{|l|}{ Moulding catheter } \\
\hline $1.5-4.0 \mathrm{~mm}$ phantoms & 0.19 & 0.34 \\
\hline $2.5-4.0 \mathrm{~mm}$ phantoms & 0.01 & 0.06 \\
\hline \multicolumn{3}{|l|}{$Q C A$ system } \\
\hline Ozaki $^{6}$ & -0.11 to -0.1 & 0.08 to 0.18 \\
\hline \multirow{2}{*}{ Keane $^{7}$} & -0.08 to 0.07 & 0.40 to 0.09 \\
\hline & -0.12 to -0.03 & 0.10 to 0.39 \\
\hline \multirow{2}{*}{\multicolumn{3}{|c|}{ Keane $^{9 \star}$}} \\
\hline & & \\
\hline $50 \%$ contrast & -0.41 to 0.01 & 0.06 to 0.20 \\
\hline $100 \%$ contrast & -0.23 to -0.01 & 0.07 to 0.28 \\
\hline Reiber $^{10}$ & -0.03 & 0.09 \\
\hline & 0.05 & 0.09 \\
\hline \multicolumn{3}{|l|}{ Haase $^{12} \dagger$} \\
\hline CMS $100 \%$ contrast & 0.18 & 0.14 \\
\hline CMS $50 \%$ contrast & 0.19 & 0.15 \\
\hline DCI $100 \%$ contrast & 0.11 & 0.06 \\
\hline DCI $50 \%$ contrast & 0.24 & 0.13 \\
\hline
\end{tabular}

${ }^{\star}$ Results for $50 \%$ and $100 \%$ contrast in the same phantoms. tResults comparing $50 \%$ and $100 \%$ contrast in cinefilm based Cardiovascular Measurement System (CMS) and Philips digital cardiac imaging system (DCI).

phantom studies overestimated diameters by up to $1 \mathrm{~mm},{ }^{18}$ while others have reported accuracies and precisions of 0.24 to $0.44 \mathrm{~mm}$ and 0.06 to $0.46 \mathrm{~mm}$, respectively. ${ }^{20}$ Three dimensional reconstruction of intravascular ultrasound has the same limitations, and is reliant on good image quality, as failure to identify the intimal border precludes reconstruction and quantification..$^{2-24}$

\section{STUDY LIMITATIONS}

The quantification method used and the error it introduces will always limit a study of this type. We have, however, endeavoured to estimate the error introduced by macrophotography, and it appears to be acceptably low.

The effects of wall elasticity on the accuracy of balloon moulding and of low pressure inflations on endothelial integrity and plaque morphology have not yet been examined. Similarly, the ability of the balloon to reproduce lumen eccentricity and complex curvature accurately needs to be validated before the catheter can be studied in vivo.

\section{CONCLUSION}

We have shown a high degree of accuracy and precision of the catheter in the quantification of simple and complex coronary phantoms between 2.5 and $4.0 \mathrm{~mm}$-the range within which most interventional work is performed. The results compare well with quantitative coronary angiography and intravascular ultrasound validation studies, and many of the well recognised problems with these two methods of imaging are circumvented by this moulding technique.

We plan to continue this work in postmortem coronary arteries, investigating the effects of elasticity and eccentric complexity on accuracy and precision, studying the efficacy of the balloon in the visualisation of stent deployment, and comparing this technique with quantitative coronary angiography and intravascular ultrasound. 
We thank Boston Scientific Corporation (USA) for the production and supply of the catheter. We gratefully acknowledge the advice of Dr Paul Davies from the University Department of Mathematics and Statistics on the statistical analysis of this paper.

1 Keren G. Intravascular ultrasound imaging: an update. In: Beyar R, Keren G, Leon M, Serruys PW, eds. Frontiers in interventional cardiology, 1st ed. London: Martin Dunitz,

2 Bland JM, Altman DG. Statistical methods for assessing agreement between two methods of clinical measurement. Lancet 1986;i:307-10.

3 Alfonso F, Macaya C, Goicolea J, et al. Angiographic changes (Dotter effect) produced by intravascular ultrasound imaging before coronary angioplasty. Am Heart $\mathcal{F}$ 1994;128:244-51.

4 Reiber JHC, Kooijman CJ, Slager CJ, et al. Coronary artery dimensions from cineangiograms - methodology and validation of a computer assisted analysis procedure. IEEE Trans Med Imaging 1984;M12:131-41.

5 Gurley JC, Nissen SE, Booth DC, et al. Influence of operator- and patient-dependent variables on the suitability of automated quantitative coronary angiography for ity of automated quantitative coronary angiography for
routine clinical use. $¥ \mathrm{Am}$ Coll Cardiol 1992;19:1237-43.

6 Ozaki Y, Keane D, Herrman JP, et al. Coronary arteriography for quantitative analysis: an experimental and clinical phy for quantitative analysis: an experimental and clinical
comparison of cinefilm and video recordings. Am Heart $\mathcal{F}$ comparison of cinef

7 Keane D, Serruys PW. Quantitative coronary angiography: an integral component of interventional cardiology. In Topol EJ, Serruys PW, eds. Current review of interventional cardiology, 2nd ed. Philadelphia: Current Medicine, 1995 205-33.

8 Reiber J. An overview of coronary quantitation techniques as of 1989. In: Reiber JHC, Serruys PW, ed. Quantitative coronary arteriography. Dordrecht: Kluwer Academic Publishers, 1991:55-132.

9 Keane D, Haase J, Slager CJ, et al. Comparative validation of quantitative coronary angiography systems. Results and implications from a multicentre study using a standardized approach. Circulation 1995;91:2174-83.

10 Reiber JHC, Serruys PW, Kooijman CJ, et al. Assessment of short-, medium-, and long-term variations in arterial short-, medium-, and long-term variations in arterial
dimensions from computer-assisted quantitation of corondimensions from computer-assisted quantitation

11 Uehata A, Matsuguchi T, Bittl JA, et al. Accuracy of electronic digital calipers compared with quantitative angiography in measuring coronary arterial diameter. Circulation 1993;88:1724-9.
12 Haase J, van der Linden MMJM, di Mario C, et al. Can the same edge detection algorithm be applied to on-line and off-line analysis systems? Validation of a new cine-film based geometric coronary measurement software. $\mathrm{Am}$ Heart f 1993;126:312-21.

13 Coy KM, Maurer G, Siegel RJ. Intravascular ultrasound maging: a current perspective. f Am Coll Cardiol 1991;18: 1811-23.

14 Kearney PP, Starkey IR, Sutherland GR. Intracoronary ultrasound: current state of the art. Br Heart f 1995; 73(suppl 2):16-25.

15 Kimura BK, Bhargava V, DeMaria AN. Values and limitations of intravascular ultrasound imaging in characterizing coronary atherosclerotic plaque. Am Heart f 1995; 130:386-96.

16 De Franco AC, Tuzcu EM, Nissen SE. Interventional applications of coronary intravascular ultrasound. In: Topol EJ, Serruys PW, ed. Current review of interventional cardiology, 2nd ed. Philadelphia: Churchill Livingstone, 1995:173-92.

17 McKay CR, Griffith J, Kerber RE, et al. Factors influencing intraluminal ultrasound image quality and arterial wall morphology [abstract]. Circulation 1989;80(suppl 2):II581.

18 Nishimura RA, Edwards WD, Warnes CA, et al. Intravascular ultrasound imaging: in vitro validation and pathologic correlation. $\mathcal{F}$ Am Coll Cardiol 1990;16:145-54.

19 Kimura BJ, Bhargava V, Palinski W, et al. Can intravascular ultrasound yield accurate measures of vascular anatomy? Documentation of the critical importance of uniform rotational velocity [abstract]. 7 Am Coll Cardiol 1994;23(suppl): tional

20 Wenguang L, Gussenhoven WJ, Zhong Y, et al. Validation of quantitative analysis of intravascular ultrasound images. Int $\mathcal{f}$ Card Imaging 1991;6:247-63.

21 Tabbara M, Kopchok G, White RA. In vitro and in vivo evaluation of intraluminal ultrasound in normal and atherosclerotic arteries. Am f Surg 1990;160:556-60.

22 Di Mario C, von Birgelen C, Prati F, et al. Three dimensional reconstruction of cross sectional intracoronary ultrasound: clinical or research tool? Br Heart f 1995; 73(suppl 2):26-32

23 Roelandt JRTC, di Mario C, Pandian NG, et al. Threedimensional reconstruction of intracoronary ultrasound images: rationale, approaches, problems, and directions. Circulation 1994;90:1044-55.

24 von Birgelen C, Di Mario C, Reimer B, et al. Threedimensional intracoronary ultrasound imaging: methodology and clinical relevance for the assessment of coronary arteries and bypass grafts. $\mathcal{F}$ Cardiovasc Surg 1996;36:12939 